\title{
História e Ensino. A Produção de Conhecimento
}

\author{
History and Education. The Production of Knowledge
}

Tudo o tempo leva. A própria vida não dura. Com sabedoria colhe a alegria de agora para a saudade futura.

Helena Kolody

Na década de 80 do século XX, pode-se dizer que ocorreu uma ruptura no debate filosófico do ensino de história. Tal ruptura deveu-se ao fato de alçar como sujeitos o professor e o estudante no fazer escolar. Estava posto, nesse contexto, o debate sobre o conhecimento histórico produzido em todos os níveis escolares, e o alicerce para o entendimento de que na escola básica e média seria produzido saber na nossa disciplina. A questão polêmica constitui campo de reflexão sobre o conhecimento em geral e específico.

Entende-se aqui por saber histórico, apesar da polêmica ainda contemporânea daí advinda, o conhecimento produzido na reflexão educacional onde professores e alunos dialogam diversamente com as tradições e fontes históricas disponíveis. O fortalecimento do debate acerca das relações entre História e Ensino amplia este campo de investigação traduzido no expressivo resultado de pesquisas apresentadas nos grandes encontros da área (Encontro Nacional de Pesquisadores de Ensino de História e Encontro Nacional Perspectivas do Ensino de História), bem como, nos simpósios regionais e nacionais de História (ANPUH).

Tal adensamento reflete-se na abertura dos debates acerca dos novos suportes, fontes e abordagens para o ensino de história, incluindo outras formas de constituição de consciência histórica, fora do ambiente escolar, e as relações que são travadas entre estes meios e a sociedade (BARCA, LEE, DICKINSON, ASHBY). 
Saberes docentes, formação de professores, formação de consciência histórica pelos jovens, metodologias de ensino e pesquisa a partir do espaço da sala de aula, currículos e práticas pedagógicas em todos os níveis, e políticas públicas e ensino de história, além de outros, são exemplos de linhas investigativas em curso que a cada dia mais ocupam espaço nos programas de pós graduação, em obras e periódicos científicos da área.

Este debate está inserido de forma exemplar em sua historicidade, especialmente, na transição política brasileira e é reflexo das novas teorias e abordagens da historiografia. As concepções historiográficas contemporâneas que articulam reflexão sobre a cultura, a política, a economia e o social-serão também as matrizes norteadoras das grandes guinadas e da ampliação das discussões acerca do ensino de história.

Nas reflexões sobre o ensino de história deságuam as contradições, proximidades e equacionamentos da historiografia contemporânea, sendo, portanto, o debate teórico-metodológico objeto privilegiado de investigação.

Reflexões sobre o lugar da História da Educação , assim como o reconhecimento, na produção historiográfica brasileira e nas atividades dos historiadores por todo o país, da necessidade de constituição de um espaço próprio para as questões relacionadas ao ensino de História constituíram parte das justificativas para a inclusão de História e Ensino como linha de pesquisa no Programa de Pós- Graduação em História Social da Universidade Estadual de Londrina. Deve-se acrescentar que, além dessa demanda por uma reflexão embasada por questões teóricas e metodológicas próprias à área, é possível amalgamar às reflexões sobre o Ensino de História, a História das instituições e políticas públicas educacionais. Este debate coloca em evidência a necessidade de constituição de um campo de investigação historiográfica, não somente do ensino de História no ambiente escolar, mas também as relações entre essa cultura escolar e outros meios que as sociedades dispõem para elaboração e reelaboração do passado.

De tal forma que, para alguns autores, não se pode separar, atualmente, o debate sobre o ensino de História do contexto no qual este é produzido. Ou seja, das relações de poder e saber, em especial das relações entre universidades, indústria cultural e ensino fundamental e médio (FONSECA, 2003). 
Nas últimas décadas do século XX, além do Estado e do mercado editorial, a mídia também se fez presente na discussão sobre o que ensinar aos jovens. Assim, como salienta a autora mencionada, discutir o ensino de História hoje, significa pensar outros espaços e formas de se educar cidadãos, principalmente numa sociedade marcada pelas diferenças e desigualdades. Uma sociedade que vive um tempo de mudanças e incertezas, de relativismos e neoliberalismos, no qual a mudança tomou um valor enquanto tal, isto é, o homem de hoje carrega em si próprio a ruptura como um desejo.

Nesta perspectiva, uma questão que se coloca é o que ensinar e preservar em relação ao passado numa sociedade que faz uma apologia à mudança? (FONSECA; FORQUIN). Tentativas como as realizadas pelos Parâmetros Curriculares Nacionais (PCNs), no Brasil, pretenderam dar uma resposta para essa questão: o que da nossa cultura, da nossa memória seria mais adequado transmitir às novas gerações. Entretanto, não se deve esquecer que o currículo é uma "invenção da tradição" como bem indica (GOODSON). Ou seja, é um discurso que atende interesses e, portanto, age no pensamento dos professores, na burocracia escolar e na indústria cultural.

Todavia, também deve-se levar em conta que o currículo formal é apenas um aspecto que opera e faz uma seleção cultural, igualmente o currículo real que é feito a partir da cultura escolar e da vida cotidiana dos alunos são dimensões que se tem que tomar como parâmetros (FONSECA; PERRENOUD; FORQUIN). Refletir sobre tais questões, inclusive sobre a nova LDB e os PCNs, nos remetem a reexaminar qual é a função e o papel da escola com relação aos saberes históricos nela transmitidos.

Diferentemente das décadas de 1970 e 1980, quando a escola era vista como um aparelho de reprodução dos valores e idéias da "classe dominante" e a História como um veículo de reprodução da memória do vencedor, nas décadas seguintes, ela é repensada como um lugar social que deve ser analisado de diferentes formas (APPLE). Não se trata apenas de um "reflexo" do funcionamento da sociedade, mas um local de conflitos de classes e de formas culturais outras, bem como um lugar de produção do conhecimento (FONSECA).

Segundo André Chervel, é inconcebível como não se percebeu durante tanto tempo o poder criativo que a escola detém e desempenha, pois ela forma 
não apenas os indivíduos, mas também uma cultura que pode penetrar, moldar e modificar a cultura da sociedade global. (CHERVEL). Isso não significa que a escola deve ser vista como "um império dentro do império", mas é necessário reconhecer a sua autonomia relativa em relação às outras dinâmicas que coexistem no campo social. (FONSECA; FORQUIN; SACRISTÁN). Dessa forma, a escola pode ser vista como dotada de uma dinâmica própria, possuidora de saberes, hábitos, valores, modos de pensar, estratégias de dominação e resistências, critérios de seleção que fazem parte daquilo que se chama "cultura escolar".

Nesse contexto, o professor de História pode fazer emergir o plural (a memória e projetos de diferenciados sujeitos sociais) ou pode perpetuar uma memória dominante. Talvez a reposta mais comum encontrada nos últimos anos para esse dilema, tanto no ensino público quanto no privado, seja a concepção do ensino temático e multicultural, como pode ser constatado nos textos dos PCNs, por exemplo. Para Selva Fonseca, essa constatação nos remete a repensar pelo menos três aspectos. Primeiro, não basta introduzir novos temas nos currículos multiculturais, se na prática, nas relações cotidianas se promove a exclusão através de brincadeiras, jogos ou formas de avaliação. Segundo, devese reconhecer que o professor não opera no vazio. Existem outros espaços educativos atuando nas concepções dos alunos como, por exemplo, a televisão, os quadrinhos ou os acontecimentos cotidianos. E terceiro, a perspectiva do ensino temático e multicultural deve vir acompanhada de uma mudança na formação dos professores: postura crítica e reflexiva, cultivo à tolerância e respeito à diversidade e às diferenças.

Podemos dizer igualmente que, na atualidade, parte das pesquisas se volta para a compreensão da lógica da História, nomeadamente no que diz respeito ao pensamento dos alunos, em especial nos trabalhos de ingleses e portugueses (LEE; BARCA) assumiu um objetivo central procurando encontrar os vários componentes dessa lógica através da produção filosófica da História, da Psicologia, em especial das teorias construtivistas do conhecimento, focalizando o seu labor investigativo no pensamento histórico dos alunos através de uma sólida fundamentação empírica, centrada, sobretudo em idéias chave como as de mudança, desenvolvimento, causa, efeito, entre outros. 
Por outro lado, autores como Rüsen, entre outros, afirmam a existência de um domínio específico do conhecimento que denominam de Didática da História, nas interfaces da investigação entre a própria epistemologia da História, tomada como referência para a construção de categorias e metodologias de análise, e seu diálogo com as outras ciências, situado naquilo que Prats denomina de encruzilhada de diversas ciências humanas, as que se ocupam tradicionalmente da aprendizagem e as que constituem a base do conhecimento que se pretende ensinar.

Entre as mudanças paradigmáticas que ocorreram no campo da história e do ensino de história a partir da década de 1980, que ampliaram as perspectivas de pesquisa, estão as propostas de investigar os processos de constituição da consciência histórica, aqui tendo como referencia epistemológica as investigações de Rüsen e Laville sobre a constituição de um pensamento sobre a história e um pensar histórico necessários para a vida prática dos seres humanos, que se levanta como um dos grandes debates atuais das investigações no campo do ensino de história.

As idéias anteriormente apresentadas constituíram o alicerce e os pilares das reflexões que foram construídas pelos membros da Área de Ensino de História do Departamento de História da UEL para a proposição da Linha de Pesquisa denominada "História e Ensino" do seu Programa de Pós-graduação em História Social, que entre outras iniciativas promoveu a edição de uma revista, Antíteses, que apresenta seu primeiro número sobre as temáticas relacionadas a esta área de conhecimento.

O título "História e Ensino. A Produção de Conhecimento" deste dossiê teve a intenção de abarcar e sublinhar os marcos do debate sobre a já superada, no sentido de não restar dúvida, discussão sobre a possibilidade de produção de conhecimento -hoje conhecido como conhecimento histórico escolar- que se constrói no fazer dos professores e estudantes no âmbito do ensino fundamental e médio, mas também, a produção das reflexões sobre ensino, instituições e políticas públicas, no meio acadêmico.

Para fazer jus a tal proposição, nosso autor convidado, Marcos Silva, que nos oferece uma contundente reflexão sobre o historiador e seu tempo, representa aqui uma geração de historiadores que ousaram trazer à baila o debate sobre o ensino de história nos moldes em que se deu a partir da década 
de oitenta do século XX. O historiador organizou a obra "Repensando a História" que concentrou naquele momento as principais referências do debate que depois muito se ampliou. Mesmo com os limites que são peculiares a uma publicação como a que aqui apresentamos, podemos visualizar, a partir dela, a grandiosidade do alcance e da perspectiva de tal ampliação.

Por último, especialmente, pela importância do ato, a primeira publicação da Linha de Pesquisa de História e Ensino deste Programa, que traz a notícia de suas primeiras dissertações defendidas na área, deve ser oferecida à memória da Professora Mariana Josefa de Carvalho Almeida, nossa pioneira e precursora na longa e trabalhosa trajetória que construiu a possibilidade de hoje nos constituirmos uma das linhas de pesquisa que contribuem para sua edificação. Para lembrar e homenagear a doçura e sabedoria que representava a prazerosa convivência com nossa queridíssima colega Mariana encontramos na obra "Sinfonia da Vida", da grande poetisa paranaense Helena Kolody, um poema intitulado "Sabedoria" (1993) o epígrafe que expressa de maneira ímpar a felicidade e tesouro que significou para nós o convívio com o jeito de ser dessa pessoa maravilhosa.

Cristiano Biazzo Simon Coodenador do Dossiê

Londrina, junho de 2009 